\title{
Cytoprotection against neutrophil derived hypochlorous acid: a potential mechanism for the therapeutic action of 5-aminosalicylic acid in ulcerative colitis
}

\author{
F Dallegri, L Ottonello, A Ballestrero, F Bogliolo, F Ferrando, F Patrone
}

\begin{abstract}
The aim of the present study was to investigate the effects of 5-aminosalicyclic acid (5-ASA) on the cell injury mediated by activated neutrophils. We used a system constituted of neutrophils, triggered with phorbol myristate acetate, and ${ }^{51} \mathrm{Cr}$-labelled Daudi cells as targets. The results show that 5-ASA is capable of efficiently preventing neutrophilmediated lysis. 5-ASA was up to 10-fold more effective than taurine, which acts as an hypochlorous acid scavenger. Moreover, 5-ASA was found to compete with taurine for the neutrophil derived hypochlorous acid. The results are consistent with the conclusion that 5-ASA is capable of limiting the neutrophil mediated cell damage by scavenging the generated hypochlorous acid. This may represent a potential mechanism for the therapeutic action of 5-ASA in ulcerative colitis.
\end{abstract}

The therapeutic benefit of 5-aminosalicylic acid (5-ASA) in ulcerative colitis is well established. ${ }^{12}$ It appears to act directly on the inflamed mucosa possibly by blocking cyclooxygenase and lipooxygenase metabolite mediated inflammation ${ }^{23}$ and/or by reducing the local generation of highly reactive oxygen species. ${ }^{+5}$ This latter possibility is particularly attractive because of the neutrophil infiltration of the colonic mucosa, coupled with the well known ability of neutrophils to produce reactive oxygen species. ${ }^{6}$ Nevertheless, to our knowledge, the actual capacity of 5-ASA to interfere with the oxidative cell damage mediated by neutrophils has not been directly proved. In the present paper, using a cytotoxicity model generally accepted to study the neutrophil mediated cellular damage (phorbol myristate acetate - triggered neutrophils plus Daudi target cells), ${ }^{78}$ we provide evidence that 5 ASA is highly effective in limiting the neutrophil cytolytic potential.

First Medical Clinic, University of Genova Medical School, Genova,

Italy

F Dallegri

L Ottonello

A Ballestrero

F Bogliolo

F Ferrando

F Patrone

Correspondence to: Dr Franco Dallegri, ISMI - Clinica Medica I Viale Benedetto XV no 6, I-16132 Genova, Italy

Accepted for publication 26 April 1989

Hanks' balanced saline solution with $1 \mathrm{mg} / \mathrm{ml}$ glucose and without phenol red (HBSS, Flow Lab, Ltd, Irvine, Scotland) was used as incubation medium. RPMI 1640 and fetal calf serum were purchased from Flow Lab. Taurine $\left(\mathrm{TauNH}_{2}\right.$ ), 5-aminosalicylic acid (5-ASA) and Triton X-100 were purchased from Sigma Chemical Co, St Louis, MO. The drug 5-ASA
( $\sim 99 \%$ pure, as assayed by Sigma; lot 15 F-0803) was dissolved at the concentration of $5 \mathrm{mmol} / \mathrm{l}$ in $0.9 \% \mathrm{NaCl}\left(37^{\circ} \mathrm{C}\right)$ immediately before each experiment. The solution of the drug was maintained in the dark to avoid 5-ASA oxidation by light. (The assays were carried out in the dark as well.) Heparin (Liquemin) was from Roche, Milan, Italy, and Ficoll-Hypaque from Nyegaard $\mathrm{Co}$, Oslo, Norway. $\mathrm{Na}_{2}\left({ }^{51} \mathrm{Cr}\right) \mathrm{O}_{4}$ was from the Radiochemical Centre, Amersham, England. Phorbol-12-myristate-13-acetate (PMA, Sigma), stored at $-20^{\circ} \mathrm{C}$ as stock solution of $2 \mathrm{mg} / \mathrm{ml}$ in dimethylsulphoxide (C Erba, Milan, Italy) was diluted in medium and used at the final concentration of $10 \mathrm{ng} / \mathrm{ml}$. 5-thio-2nitrobenzoic acid (Nbs) was prepared by reducing 5-5'-dithiobis (2-nitrobenzoic) acid (Sigma), as described by Aune and Thomas. ${ }^{9}$ Hypochlorous acid was generated by adding sodium hypoclorite $(\mathrm{NaOCl}, \mathrm{BDH}$ Ltd, Pool, UK) into solution buffered at $\mathrm{pH} 7 \cdot 4 .^{10}$

\section{NEUTROPHILS}

Heparinised (heparin $10 \mathrm{U} / \mathrm{ml}$ ) venous blood was obtained from healthy male volunteers. Neutrophils were isolated by dextran sedimentation and subsequent centrifugation on a FicollHypaque density gradient, as previously described. ${ }^{10}$ Contaminating erythrocytes were removed by hypotonic lysis. ${ }^{10}$ Neutrophils were then washed three times with HBSS and resuspended in HBSS. Final cell suspensions contained $97 \%$ or more neutrophils and more than $98 \%$ viable cells, as evaluated by the ethidium bromide fluorescein diacetate test. ${ }^{10}$

\section{DAUDI CELLS}

The Daudi cell line (B lymphoblasts, kindly supplied by Prof G Damiani, Department of Biochemistry, University of Genova, Italy) was grown in suspension (RPMI-FCS) and subcultured every four to five days. " The cells were washed three times with HBSS and resuspended in HBSS before use. Daudi cells were labelled with $100-200 \mu \mathrm{Ci}$ sodium ${ }^{51} \mathrm{Cr}$-chromate by incubating for one hour at $37^{\circ} \mathrm{C} . "$ After being washed, the cells were resuspended in HBSS.

\section{CYTOLYTIC ASSAY}

Daudi cell lysis by neutrophils in the presence of phorbol myristate acetate was measured using a ${ }^{51} \mathrm{Cr}$ release method. ${ }^{10}$ The experiments were carried out in duplicate using $2 \times 10^{6}$ neutrophils, 
Figure 1: Inhibition of the neutrophil cytolytic activity (ordinate) by 5-ASA. Results are expressed as mean (1)SD of at least three experiments. The $\%{ }^{\text {s }} \mathrm{Cr}$ release from labelled Daudi cells, incubated with phorbol myristate acetate triggered neutrophils in the absence of $5-A S A$, was $27 \cdot 6(4 \cdot 3)$ $(\times(1) S D, n=4)$. The compound 5-ASA had no effect on the ${ }^{\text {S1 }} \mathrm{Cr}$ release from Daudi cells incubated in absence of neutrophils.
Figure 2: Inhibition of the hypochlorous acid recovery (measured as TauNHCl) from phorbol myristate acetate triggered neutrophils by 5-ASA. Results are expressed as mean (1) SD of at least three experiments. The TauNHCl recovery from neutrophils in the absence of 5-ASA was: absence of 5-ASA was:
$56: 88(4 \cdot 6) \mathrm{nmol} / 10^{6}$ $56: 88(4 \cdot 6) \mathrm{nmol} / 10^{6}$
neutrophils $/ 1 \mathrm{~h}(\times(1) S D$, $n=4$ ).

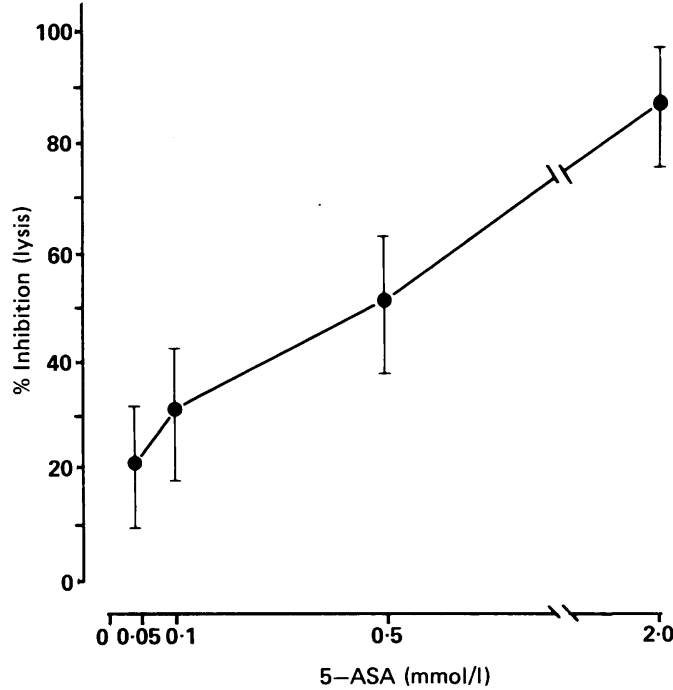

$5 \times 10^{5}$ Daudi cells, and $10 \mathrm{ng} / \mathrm{ml}$ phorbol myristate acetate in a final volume of $1 \mathrm{ml}$. Tests were done in Falcon Plastic tubes $(17 \times 100 \mathrm{~mm}$, Falcon Plastic, Oxnard, Calif) and in a shaking water bath $(100 \mathrm{rpm})$ at $37^{\circ} \mathrm{C}$. After incubation for two hours, the ${ }^{51} \mathrm{Cr}$ release from labelled target cells was determined in the cell free supernatants. The percentage of cytolysis ( $\%$ ${ }^{51} \mathrm{Cr}$ release) was calculated according to the formula $(E-S) /(T-S) \times 100$, where $E$ is the cpm released in the presence of effectors, $T$ is the cpm released after lysing target cells with 5\% Triton $\mathrm{X}-100, \mathrm{~S}$ is the cpm spontaneously released by target cells in the absence of effectors (in each case $\leqslant 10 \%$ ).

\section{HY POCHLOROUS ACID ASSAY}

The generation of hypoclorous acid by neutrophils in the presence of phorbol myristate acetate was measured by the taurine $\left(\mathrm{TauNH}_{2}\right)$ trapping technique, ${ }^{12}$ as previously. described. ${ }^{10}$ Briefly, $1 \times 10^{6}$ neutrophils and phorbol myristate acetate $10 \mathrm{ng} / \mathrm{ml}$ were incubated $\left(37^{\circ} \mathrm{C}\right.$, one hour) in a final volume of $1 \mathrm{ml}$ in the presence of $20 \mathrm{mmol} / 1$ $\mathrm{TauNH}_{2}(17 \times 100 \mathrm{~mm}$ Falcon Plastic tubes, shaking water bath at $100 \mathrm{rpm}$ ). After incubation, the amount of TauNHCl, generated by the reaction between hypochlorous acid and

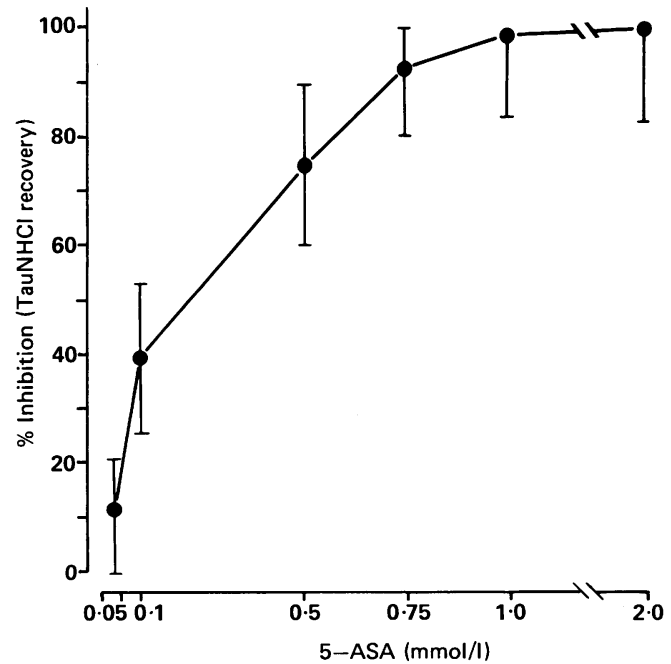

$\mathrm{TauNH}_{2}, \quad\left(\mathrm{TauNH}_{2}+\right.$ hypochlorous acid $\rightarrow$ $\mathrm{TauNHCl}+\mathrm{H}_{2} \mathrm{O}$ ) was determined in the cell free supernatants by measuring spectrophotometrically $\left(\mathrm{OD}=412 \mathrm{~nm}, \varepsilon=1.36 \times 10^{+} \mathrm{mol} / \mathrm{l} / \mathrm{cm}\right)$ the TauNHCl mediated oxidation of 5-thio-2nitrobenzoic acid. ${ }^{12} \mathrm{~A}$ series of experiments was also planned to detect the ability of 5-ASA to limit the formation of $\mathrm{Tau} \mathrm{NHCl}$ from reagent hypochlorous acid and $\mathrm{TauNH}_{2}$. These experiments were carried out by adding reagent hypochlorous acid $(40 \mu \mathrm{mol} / \mathrm{l})$ to a mixture of $\mathrm{TauNH}_{2}(20 \mathrm{mmol} / \mathrm{l})$ and 5-ASA in doses ranging from 0.05 to $1.0 \mathrm{mmol} / \mathrm{l}$ (final volume of the reaction $=1 \mathrm{ml}$ ). After incubation for 10 minutes at $37^{\circ} \mathrm{C}$, the amount of the generated TauNHCl was measured as described above.

\section{OXYGEN CONSUMPTION ASSAY}

The oxygen consumption by neutrophils was measured polarographically using a Clark electrode (Oxygen Monitor, Yellow Springs Instrument Co, Yellow Spring, Ohio) and using the technique described by Metcalf and coworkers. ${ }^{13}$ Cell suspensions of $8 \times 10^{6}$ neutrophils in $2 \mathrm{ml}$ HBSS were agitated continuously at $37^{\circ} \mathrm{C}$. Oxygen consumption was measured after stimulation with phorbol myristate acetate (10 $\mathrm{ng} / \mathrm{ml}$ ) and the results expressed as nanomoles of oxygen consumed by $4 \times 10^{6}$ neutrophils per minute.

\section{MYELOPEROXIDASE ASSAY}

The myeloperoxidase activity released by neutrophils $\left(10^{6} \mathrm{cell} / \mathrm{s} / \mathrm{ml}\right)$, incubated (one hour, $37^{\circ} \mathrm{C}$ ) with $10 \mathrm{ng} / \mathrm{ml}$ phorbol myristate acetate, was determined in cell free supernatants as previously described ${ }^{10}$ Briefly, the myeloperoxidase assay was done by using $0.167 \mathrm{mg} / \mathrm{ml} 0$ dianisidine (Sigma) and $0.1 \mathrm{mmol} / 1 \mathrm{H}_{2} \mathrm{O}_{2}$ in 50 $\mathrm{mmol} / \mathrm{l}$ phosphate buffer $(\mathrm{pH}=6)$. One unit of enzyme activity was defined as that oxidising $1 \mu \mathrm{mol} 0$-dianisidine $/ \mathrm{min} / 25^{\circ} \mathrm{C}(\mathrm{od}=550, \varepsilon=$ $11.3 \mathrm{mmol} / \mathrm{l} / \mathrm{cm})$.

\section{Results}

As shown in Figure 1, 5-ASA inhibited the neutrophil lytic activity in a dose dependent manner. Moreover, such a neutrophil function was almost completely inhibited by $20 \mathrm{mmol} / \mathrm{l}$ taurine $\left(\mathrm{TauNH}_{2}\right)$ which traps the neutrophil derived hypochlorous acid yielding TauNHCl' $\left(\%{ }^{51} \mathrm{Cr}\right.$ release from labelled Daudi cells incubated with phorbol myristate acetate triggered neutrophils: $3.5(2.7)$ and $28.8(3.2)$ in the presence and absence of $20 \mathrm{mmol} / \mathrm{l} \mathrm{TauNH}_{2}$ respectively, $\times(1 \mathrm{SD}), \mathrm{n}=3)$.

As depicted in Figure 2, 5-ASA lowered the recovery of TauNHCl from phorbol myristate acetate-triggered neutrophils incubated in the presence of $\mathrm{TauNH}_{2}(20 \mathrm{mmol} / \mathrm{l})$. This suggests that 5-ASA is likely to compete with $\mathrm{TauNH}_{2}$ for the hypochlorous acid generated by neutrophils. Consistent with such a possibility, 5-ASA limited the formation of $\mathrm{TauNHCl}$ from reagent hypochlorous acid and $\mathrm{TauNH}_{2}$ in a dose dependent manner (Fig 3). Thus, it appears that 5-ASA inhibits the neutrophil cytolysis 
Figure 3: Effect of various doses of 5-ASA on the TauNHCl recovery from a system constituted of reagent hypochlorous acid 40 umol/l) and $\mathrm{TauNH}_{2}(20$ mmol/l). Tests were performed in a final volume of $1 \mathrm{ml}$.

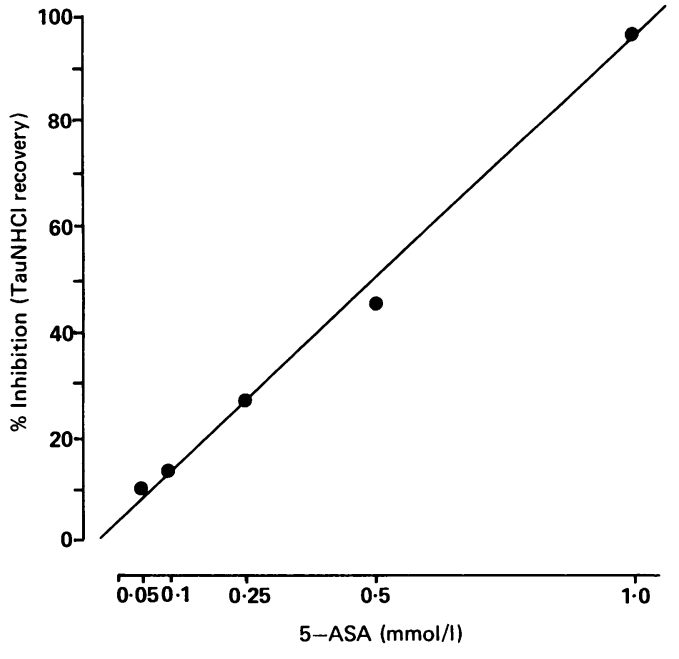

primarily by trapping the generated hypochlorous acid.

The compound 5-ASA gave only slight inhibition of the neutrophil oxygen uptake and myeloperoxidase positive primary granule exocytosis. When used at the concentration of $1 \mathrm{mmol} / \mathrm{l}$, 5-ASA inhibited the neutrophil oxygen consumption by $15-8 \%$. Concentrations of 5-ASA lower than $1 \mathrm{mmol} / \mathrm{l}$ were completely ineffective (oxygen consumption by phorbol myristate acetate triggered neutrophils in the absence of the drug: $8.74(0.70) \mathrm{nmol}$ oxygen per $4 \times 10^{6}$ cells per minute, $\left.\times(1 \mathrm{SD}), \mathrm{n}=3\right)$. Finally, a slight inhibition $(18-6 \%)$ of the myeloperoxidase release from neutrophils was only observed using relatively high doses (1 $\mathrm{mmol} / \mathrm{l}$ ) of 5-ASA (myeloperoxidase release from phorbol myristate acetate triggered neutrophils in the absence of the drug: $2.86(0.32) \mathrm{mU} / 10^{6}$ cells/lh, $\times(1 S D) n=3)$.

\section{Discussion}

Our results suggest that 5-ASA is capable of inhibiting the neutrophil cytolytic efficiency by scavenging the generated hypochlorous acid $(\mathrm{HOCl})$. In agreement with reports from other authors, ${ }^{714}$ the generation of hypochlorous acid by the neutrophil myeloperoxidase pathway $\left(\mathrm{H}_{2} \mathrm{O}_{2}+\mathrm{Cl}^{-} \stackrel{\mathrm{MPO}}{\rightarrow} \mathrm{HOCl}+\mathrm{H}_{2} \mathrm{O}\right)$ is crucial in promoting the neutrophil-dependent cell damage. In fact, $\mathrm{TauNH}_{2}$, capable of efficiently trapping the generated hypochlorous acid to yield TauNHCl, ${ }^{12}$ inhibited the lysis. When compared on a molar basis, 5-ASA was much as 10-fold more effective than $\mathrm{TauNH}_{2}$ in reducing the neutrophil lytic activity. Also, 5-ASA was found to efficiently compete with $\mathrm{TauNH}_{2}$ for reagent or neutrophil derived hypochlorous acid, lowering the production of TauNHCl. Thus, it appears that the reaction between 5-ASA and hypochlorous acid is efficient enough to protect the target cells from the neutrophil delivered hypochlorous acid dependent attack. Consistent with such a conclusion, 5-ASA was found to reduce the lysis of fibroblasts by a neutrophil free myeloperoxidase- $\mathrm{H}_{2} \mathrm{O}_{2}$-Cl-system, ${ }^{15}$ presumably able to produce hypochlorous acid."

The ability of 5-ASA reported here to limit the neutrophillytic efficiency observed at 5-ASA doses well within those detectable in the distal part of the intestinal lumen, ${ }^{16}$ raises the possibility that this effect of the drug may contribute to its therapeutic activity in ulcerative colitis. This does not contradict the view that 5-ASA may also act by suppressing the production of prostaglandins or leucotrienes or both, ${ }^{510}$ although the interference with the arachidonic acid metabolism has been reported to occur at doses of 5-ASA clearly higher than those used in the present set.

Moreover, owing to the wide range of biologic activities exerted by hypochlorous acid, ${ }^{1+}$ the cytoprotection against neutrophil attack is likely to be only one of the consequence of the hypochlorous acid-5-ASA interaction. In fact, the hypochlorous acid capacity of activating the neutrophil latent collagenase and inactivating proteinase inhibitors ${ }^{14}$ suggests that the ability of 5-ASA to scavenge neutrophil derived hypochlorous acid may limit the degraradion of connective tissue components other than the tissue cell damage. Consistent with this view, 5 ASA has been recently shown to limit the inactivation of $\alpha_{1}$-antiproteinase by reagent hypochlorous acid. ${ }^{17}$

This work was supported by Italian CNR grants n 88.00801.44/ 115.11547 (Finalised Project 'Oncology') and n 87.01499.04 115.02235)

1 Habal FM, Greenberg GR. Treatment of ulcerative colitis with oral 5-aminosalycylic acid including patients with adverse reactions to sulfasalazine. Am f Gastroenterol 1988; 83: 15-9.

2 Meyers S. The place of oral 5-aminosalicyclic acid in the therapy of ulcerative colitis. Am 7 Gastroenterol 1988; 83 . 64-7.

3 Craven PA, Pfanstiel J, Saito R, De Rubertis FR. Action of sulfasalazine and 5-aminosalicylic acid as reactive oxygen scavengers in the suppression of bile acid-induced increases in colonic epithelial cell loss and proliferative activity. in colonic epithelial cell loss and

4 Del Soldato P, Campieri M, Brignola C, et al A possible Del Soldato P, Campieri M, Brignola C, et al. A possible
mechanism of action of sulfasalazine and 5-aminosalicylic acid in inflammatory bowel diseases: interaction with oxygen free radicals. Gastroenterology 1985; 89: 1215-6.

5 Nielsen $\mathrm{OH}$, Bukhave K, Elmgreen J, Ahnfelt-Ronne I Inhibition of 5-lipoxygenase pathway of arachidonic acid metabolism in human neutrophils by sulfasalazine and 5 aminosalicylic acid. Dig Dis $S c i$ 1987; 32: 577-82.

6 Henson PM, Johnston RB Jr. Tissue injury in inflammation. Oxidants, proteinases and cationic proteins. 7 Clin Invest 1987; 79: 669-74.

7 Clark RA. Extracellular effects of the myeloperoxidasehydrogen peroxide-halide system. In: Weissmann $G$, ed. Advances in inflammation research, Vol 5 . New York: Raven Advances in inflammatio

8 Becker EL. The cytotoxic action of neutrophils on mammalian cells in vitro. Prog Allergy 1988; 60: 183-208.

9 Aune TM, Thomas EL. Accumulation of hypothiocyanite ion during peroxidase-catalyzed oxidation of thiocyanate ion. Eurf Biochem 1977; 80: 209-14.

10 Dallegri F, Patrone F, Ballestrero A, Frumento G, Sacchetti C. Inhibition of neutrophil cytolysin production by targe cells. Blood 1986; 67: 1265-72.

11 Dallegri F, Patrone F, Frumento G, Ballestrero A, Sacchetti C. Down-regulation of $\mathrm{K}$ cell activity by neutrophils. Blood 1985; 65: 571-7.

12 Weiss SJ, Klei R, Slivka A, Wei M. Chlorination of taurine by human neutrophils. Evidence for hypochlorous acid human neutrophils. Evidence for hypoc

13 Metcalf JA, Gallin II, Nauseef WM, Root RK, Laboratory manual of neutrophil function. New York: Raven Press, 1986 : manual

14 Test ST, Weiss SJ. The generation and utilization of chlorinated oxidants by human neutrophils. Adv Free Radical Biol Med 1986; 2: 91-116.

15 Molin L, Stendahl $O$. The effect of sulfasalazine and its active components on human polymorphonuclears leukocyte function in relation to ulcerative colitis. Acta Med Scand 1979; 206: 451-7.

16 Hoult JRS. Pharmacological and biochemical actions of sulphasalazine. Drugs 1986; 32 [suppl 1]: 18-26.

17 Aruoma OI, Wasil M, Halliwell B, Hoey BM, Butler J. The scavenging of oxidants by sulphasalazine and its metabolites. A possible contribution to their anti-inflammatory effects? Biochem Pharmacol 1987; 21: 3739-42. 